\title{
Chitosan Solution Containing Zein and Essential Oil as Bio Based Coating on Packaging Paper
}

\author{
Urška Vrabič Brodnjak *(D) and Katarina Tihole \\ Department of Textiles, Graphic Arts and Design, Faculty of Natural Sciences and Engineering, University of \\ Ljubljana, Snežniška 5, 1000 Ljubljana, Slovenia; katarina.tihole@gmail.com \\ * Correspondence: urska.vrabic@ntf.uni-lj.si; Tel.: +386-1-200-32-89
}

Received: 3 April 2020; Accepted: 21 May 2020; Published: 22 May 2020

\begin{abstract}
Modifications of the packaging paper surface play an important role in a variety of industries, especially in the food sector. Uncoated paper has poor water and oil barrier properties due to its porous structure. In this study, packaging paper was successfully coated with six different coating solutions containing combinations of chitosan, zein and rosemary essential oil. The chitosan and zein were actually coated in two layers; the mixed chitosan-rosemary oil and the mixed zein-rosemary oil were each applied as one layer to the paper. The results showed increased oil barrier properties in the papers coated with mixed zein-rosemary oil and reduced water permeability in the papers coated with the chitosan-rosemary oil coating solution. The result of this two-layer coating showed excellent water (Cobb60 value of $2.18 \mathrm{~g} / \mathrm{m}^{2}$ ) and oil barrier properties. All the coated papers showed a high thermal stability, especially those coated with chitosan, zein and rosemary oil layer by layer. Scanning electron microscopy was used to verify the surface differences of the coated papers, such as the closed structure, pores and smoother surface, especially in the layer-wise coated samples. Due to their good mechanical and chemical properties, coated papers with rosemary oil can be used in many applications, possibly also in the field of repellents.
\end{abstract}

Keywords: dual layer; rosemary oil; absorptiveness; thermogravimetric analysis; properties

\section{Introduction}

Packaging paper plays an important role in many industrial sectors. In general, packaging paper can be exposed to many external environmental influences such as humidity, temperature, stress, forces, pressure and chemical impacts. [1,2]. Therefore, modifications of the paper surface play an important role in a variety of industries. Namely, unmodified paper has poor water and oil resistance due to its porous structure and the presence of hydroxyl groups [1,2]. There are also lower tensile properties as well as tearing and bending strengths, which are important for packaging production. Lamination and coatings usually enhance the paper properties. In recent years, many researchers have carried out applications with bio-based coatings to achieve adequate paper properties [3-6]. In the last decade, new technologies for food packaging have come forth, including active packaging among the most promising innovations. It consists in incorporating active compounds into the packaging material, which are useful for food protection as well as in terms of antioxidant and/or antimicrobial activity. Recently, polysaccharides have become widely used as coating solutions, including chitin, chitosan and starches. The availability on the market and great properties such as non-toxicity, gas, aroma and grease barriers make it possible to use these materials in many applications [7]. On the other hand, polysaccharides have low hydrophilicity and thus limited use in materials where water vapour barriers are of the utmost importance [8,9].

Chitosan, a non-toxic and widely used polysaccharide, is obtained through the deacetylation of chitin [8]. Due to its properties such as high crystallinity and hydrogen bonding between molecular 
chains with high oxygen properties, it has aroused interest in food packaging for edible films and coatings [9-12]. One of the advantages of chitosan is its high grease barrier properties, which are due to its positive charge at the amino group under acidic conditions, as it binds negatively charged molecules [8]. For its good barrier properties (antimicrobial, mechanical, against grease, oxygen) chitosan coatings can also be used as a barrier in packaging [11-14]. In several chitosan coatings, additional biopolymers have been added to achieve hydrophobic properties of the substrate [14-17].

Zein is a biodegradable polymer obtained from corn waste. Due to its molecular structure, zein has a good resistance to water but poor resistance to grease [18]. Many authors have improved zein paper coatings or packaging films with additional additives like orange peel oil, tea extract powder, Zataria multiflora Boiss., essential oil, tannic acid, etc. [19-22]. Interest is growing in incorporating antioxidant and antimicrobial agents into zein coatings or films to produce functional films for food applications [23]. Gagon et al. presented the fabrication of polypropylene packaging material with zein to improve antimicrobial properties [23].

Chitosan and zein have mostly been used separately in the coating industry, but there are only few studies with a combination of the mentioned components [24-26].

On the other hand, there is a wide range of research on applications and the use of essential oils in paper coatings to obtain antimicrobial, repellent and oil-resistant materials [21,27-31]. Some studies have shown that essential oils should have a high potential as natural pesticides [32-34]. A few examples of studies have shown that rosemary essential oil has been effectively used in packaging materials as a natural insecticide (repellent, digestive, growth retardant) [35-38].

Abdollahi et al. studied the changes of the water vapour properties of chitosan film with incorporated rosemary essential oil [39]. The amount of $1.5 \% v / v$ rosemary oil was sufficient to increase the hydrophobicity of chitosan-rosemary packaging film. The antioxidant and antimicrobial properties of the essential oils are attributed to the phenolic compounds, which cause the reduction of the lipid oxidation and microorganisms growth in food, which was confirmed by Siripatrawan et al. [40]. Pires et al. successfully developed chitosan/montmorillonite bionanocomposites incorporated with rosemary essential oil [41]. They proved that the novel active packaging was appropriate for the packaging of the fresh poultry meat. On the other hand, Licciardello et al. showed potential in terms of the repellent activities of packaging films coated with rosemary oil, against the red flour beetle [35,42].

The literature shows no record of previous research based on dual layer chitosan and mixtures of Zein-rosemary oil as paper coatings.

The aim of our study was to evaluate the effect of rosemary oil in bilayer paper coating with the addition of chitosan and zein. In addition, the influence of different combinations of biopolymers on the mechanical and physical properties of coated papers was determined. Our research was focused on the influence of all three components, which has a great influence on the coatings industry, had great water and oil barrier properties and could be used in the packaging field.

\section{Materials and Methods}

\subsection{Materials}

Chitosan (molecular weight $20 \mathrm{kDa}$, deacetylation degree $<85 \%$ ), was obtained from Sigma Aldrich (St. Louis, MO, USA). Acetic acid (98\%), ethanol (95\%) and zein (from maize; with molecular weight $20 \mathrm{kDa}$ ) were obtained from Sigma Aldrich. Rosemary essential oil (Rosemarinus officinalis L.) was purchased from Merck (Darmstadt, Germany). All the chemicals used were of analytical grade. In the research, an uncoated paper sample with specified grammage $80 \mathrm{~g} / \mathrm{m}^{2}$ was used [7]. 


\subsection{Coating Solutions and Procedures}

\subsubsection{Coating Solutions}

Firstly, all the solutions were prepared separately and afterwards layer-by layer coating was applied.

Chitosan solution was prepared by dissolving $2 \mathrm{~g}$ of chitosan in $100 \mathrm{~mL}$ of $2 \%$ acetic acid and then adding the $50 \mathrm{~mL}$ of glycerol. The solution was then mixed for $10 \mathrm{~min}$ at a stirring speed of $800 \mathrm{rpm}$ (at $85^{\circ} \mathrm{C}$ ). After stirring, it was cooled down to the temperature of $23^{\circ} \mathrm{C}$.

The zein solution was prepared by dissolving $30 \mathrm{~g}$ of zein powder $(30 \%, w / v)$ in ethanol/water $(85 \% / 15 \%, v / v)$ to a total volume of $100 \mathrm{~mL}$. The solution was mixed for $5 \mathrm{~h}$, at room temperature, and stirred at a speed of $800 \mathrm{rpm}$. Before use, the solution was stirred for another $20 \mathrm{~min}$.

The appropriate amounts of rosemary essential oil were added to the solution, to reach a final concentration of $1.5 \% v / v$, on the basis of the chitosan-prepared solution. The solution was homogenized with an Ultra-Turrax (IKA T25-Digital Ultra-Turrax, Staufen, Germany) at $5000 \mathrm{rpm}$ for $3 \mathrm{~min}$.

The same procedure was performed for the zein solution with the rosemary essential oil.

\subsubsection{The Coating Procedure}

After the solutions were prepared, the coatings were applied with a coater (K-Coater K101, RK PrintCoat Instruments Ltd, Litlington, Royston, UK) on the paper samples in an MD direction. This machine used standard wire-wound bars to produce a uniform and repeatable coating. The samples were coated on a coating table at an ambient temperature using a $120 \mu \mathrm{m}$ blade. The coated samples were then dried (at $40{ }^{\circ} \mathrm{C}$ for $10 \mathrm{~min}$ ). A $5 \mathrm{~g} / \mathrm{m}^{2}$ of coating was applied to each paper. Grammage $\left(\mathrm{g} / \mathrm{m}^{2}\right)$ was obtained by subtracting from the weight of a defined area of coated paper, the weight of the same size area of the uncoated paper.

The Coating Procedure at Dual Layer Coatings

When the first layer was applied to the paper, the coated sample was dried $\left(40^{\circ} \mathrm{C}\right.$ for $\left.10 \mathrm{~min}\right)$. After that the second layer of coating was applied the same drying procedure followed.

The paper sheets were coated using four variations of different coating mixtures and the analysed samples in the research were:

(1) Uncoated paper (U);

(2) Chitosan (first layer) and zein (second layer) in the layer-by-layer coating procedure (CZ) (ratio 1:1);

(3) Blend of zein and rosemary oil coating on paper (one layer) (ZR);

(4) Blend of chitosan and rosemary oil coting on paper (one layer) (CR);

(5) Chitosan (first layer) and blend of zein and rosemary oil (second layer) in the layer-by-layer coating procedure (CZR) (ratio 1:1);

(6) Paper with chitosan alone in one layer (C);

(7) Paper with zein alone in one layer (Z).

\subsection{Analysis of the Papers}

\subsubsection{Basic Properties}

To determine the amount of coating on the paper, the basis weight (grammage) was determined according to the standard ISO 536:2012 [43]. The standards defined the analysis of 10 samples, which should be cut to a size of $10 \mathrm{~cm} \times 10 \mathrm{~cm}$ and weighed.

The thickness of the samples was determined with a digital micrometre Mitutoyo Corporation, Kanagawa, Japan, to an accuracy of $0.0001 \mu \mathrm{m}$. The measurements of the samples were performed at 10 random locations on each sample. The density and specific surface area were calculated according to standard ISO 534:2011 [44]. 


\subsubsection{Moisture Content, Absorptiveness and Water Vapour Permeability}

The moisture content was determined at ISO 287:2017 [45]. The weight loss after drying in a laboratory oven at $105 \pm 1{ }^{\circ} \mathrm{C}$ for the weight of each paper sample (5 replicates) was measured.

Absorptiveness was measured as described in standard ISO 535:2014 [46]. A $100 \mathrm{~mL}$ quantity of water was in contact with the paper for $60 \mathrm{~s}$ (10 samples) and the weight differences were compared.

The water vapour permeability (WVP) was determined as described in standard ISO 2528 [47]. The test cups were filled with water and a single sample was placed between the cup and the ring lid of each cup. The samples (three parallels) with the exposed area of $50 \mathrm{~cm}^{2}$ were tested at $90 \% \pm 2 \% \mathrm{RH}$ and $38 \pm 2{ }^{\circ} \mathrm{C}$ for $24 \mathrm{~h}$.

\subsubsection{Grease Resistance}

Grease resistance was performed according to the modified TAPPI test T-507. A $(10 \mathrm{~cm} \times 10 \mathrm{~cm})$ sample of blotter paper was saturated with vegetable oil that had been dyed red using Oil Red O (Sigma Aldrich). A dyed blotting paper square was placed on each paper sample. A clean sheet of blotting paper was then placed under each paper sample to absorb the oil that had penetrated the sample. The stacks of samples were placed between 2 pressure blocks made of smooth plastic sheets weighing $720 \mathrm{~g}$ each and then tested at a room temperature of $23^{\circ} \mathrm{C}$ and a $\mathrm{RH}$ of $50 \% \pm 5 \%$. The coated and uncoated samples were tested every hour for a full $8 \mathrm{~h}$. The area of the blotters dyed with oil was determined using a dot-count method. Smaller stains per hour on coated paper showed a higher grease resistance.

\subsubsection{Mechanical Properties}

Tensile strength (TS) and the elongation at break (E) of papers were analysed in the standard atmosphere at $23{ }^{\circ} \mathrm{C}$ of temperature and $50 \%$ of relative humidity on a tensile testing machine Instron 6022 (Norwood, MA, USA). The cross-speed head was $0.15 \mathrm{~mm} / \mathrm{s}$ and the paper stripes of $18 \mathrm{~cm}$ in length and $1.5 \mathrm{~cm}$ in width (in machine-MD and cross-CD direction) were used.

After measuring the tensile strength, the tensile index was calculated. The tensile index is the tensile strength divided by the basis weight, and the unit is $\mathrm{kN} \cdot \mathrm{m} / \mathrm{g}$.

The bending resistance was determined as described in the standard TAPPI T511 [48]. Specimen preload was $1000 \mathrm{~g}$, where $175 \mathrm{bending} /$ minute proceeded.

Bursting strength was determined according to the standard method EN ISO 13938/2:2019 [49] and ten replicas per sample were done. The pressure exerted by a rubber membrane with a diameter of $30.5 \mathrm{~mm}$ increased continuously until the sample broke.

Tear resistance was processed as described in standard ISO 1974:2012 ([50], Elmendorf method, at $23{ }^{\circ} \mathrm{C}$ and $50 \% \mathrm{RH}$ ). Tear resistance was determined in $\mathrm{mN}$, as the force required to tear a sample after a cut was already started (MD and CD directions). If the tensile strength is normalised in relation to the basis weight, the tensile index can be calculated and the unit is $\mathrm{mN} \cdot \mathrm{m}^{2} / \mathrm{g}$.

\subsubsection{Thermogravimetric Analysis (TGA)}

Thermogravimetric analysis (TGA) test was carried out with a thermogravimetric analyser (Mettler Toledo, Columbus, OH, USA). All the analysed samples with a weight around 5-10 mg were heated under dynamic mode, in $\mathrm{N}_{2}$ atmosphere, at a flow rate of $40 \mathrm{~mL} / \mathrm{min}$ from 30 to $600{ }^{\circ} \mathrm{C}$. The heating rate was $10^{\circ} \mathrm{C} / \mathrm{min}$ (low rate $50 \mathrm{~mL} \cdot \mathrm{min}^{-1}$ ) in order to prevent any thermoxidative degradation.

\subsubsection{Surface Properties—Scanning Electron Microscope (SEM)}

Surface properties were analysed with a scanning electron microscope (JSM-6060 LV, JEOL, Tokyo, Japan). The instrument operated at $10 \mathrm{kV}$ and at the magnification 500 $\times$. 


\subsubsection{Statistics}

The results for the grammage, thickness, density and the specific surface volume are presented as a mean \pm standard deviation. An analysis of variance (ANOVA) was performed.

\section{Results and Discussion}

\subsection{Basic Properties}

The basic properties (grammage, thickness, density and specific surface volume) of the analysed samples are shown in Table 1. The grammage, caliper and moisture profiles in the cross and machine directions have an enormous influence on the coating results. Grammage and thickness have an influence on the tensile properties of the paper. The thickness also influences the bending and tearing stiffness of the paper. The results show that $5 \mathrm{~g} / \mathrm{m}^{2}$ coating was successfully applied to the samples.

Table 1. Determination of the basic properties of uncoated (U), chitosan and zein coated (CZ), blend zein and rosemary oil coated (ZR), blend chitosan and rosemary oil coated (CR), chitosan and blend zein and rosemary oil coated (CZR), pure chitosan in one layer coated $(C)$ and the pure zein in one layer coated $(Z)$ paper samples.

\begin{tabular}{|c|c|c|c|c|}
\hline Sample & $\begin{array}{l}\text { Grammage } \\
\left(\mathrm{m} / \mathrm{g}^{2}\right)\end{array}$ & $\begin{array}{l}\text { Thickness } \\
\quad(\mu \mathrm{m})\end{array}$ & $\begin{array}{l}\text { Density } \\
\left(\mathrm{kg} / \mathrm{m}^{3}\right)\end{array}$ & $\begin{array}{l}\text { Specific Surface Volume } \\
\left(\mathrm{m}^{3} / \mathrm{kg}\right)\end{array}$ \\
\hline $\mathrm{U}$ & $80 \pm 0.02$ & $121 \pm 0.5^{a}$ & $661.57 \pm 0.4$ & $0.00151 \pm 0.0002$ \\
\hline $\mathrm{CZ}$ & $85 \pm 0.03$ & $124 \pm 12^{a}$ & $685.48 \pm 1.0$ & $0.00146 \pm 0.0003$ \\
\hline $\mathrm{ZR}$ & $85 \pm 0.02$ & $123 \pm 1^{\mathrm{a}}$ & $691.06 \pm 0.5$ & $0.00145 \pm 0.0002$ \\
\hline $\mathrm{CR}$ & $85 \pm 0.01$ & $123 \pm 0.5^{a}$ & $691.06 \pm 0.7$ & $0.00145 \pm 0.0002$ \\
\hline CZR & $85 \pm 0.03$ & $124 \pm 1^{\mathrm{a}}$ & $685.48 \pm 1.1$ & $0.00146 \pm 0.0001$ \\
\hline C & $85 \pm 0.03$ & $124 \pm 2^{a}$ & $691.06 \pm 1.0$ & $0.0145 \pm 0.0001$ \\
\hline $\mathrm{Z}$ & $85 \pm 0.02$ & $124 \pm 1^{\mathrm{a}}$ & $691.06 \pm 0.9$ & $0.0145 \pm 0.0001$ \\
\hline
\end{tabular}

${ }^{a}$ Means of ten replicates \pm standard deviation.

In order to develop both water- and oil-resistant paper, a two-layer paper coating (CZR) was developed, which was also biodegradable. The chitosan, as the first layer, was in fact completely biodegradable. The second layer used was a zein coating with an enclosed essential oil, which is a product derived from corn, which is biodegradable and food safe. No differences in the thickness were found between the samples.

\subsection{Moisture, Water and Grease Barrier Properties}

Uncoated paper has a hydrophilic nature and due to its porous structure, it has a high capability of water and moisture uptake. To analyse the hydrophilic/hydrophobic properties of the paper coatings, moisture, water absorptiveness and water vapour permeability were determined (Figure 1).

As expected, the worst water barrier properties were found in the uncoated paper. For the coated paper, the best moisture, Cobb and WVP values were found for the CRZ sample paper. The goal of our research was to make the paper water- and oil- resistant, which was successfully achieved by a layer-by-layer CRZ coating. The coating with the first chitosan and the top zein layer with essential oil actually contributed to the hydrophobicity and hydrophilicity. The zein layer was applied to the top of the paper because of its hydrophobic nature and therefore water could not penetrate the paper. The chitosan layer was chosen as the first layer on the paper because of its hydrophilic and oleophobic properties.

From the results we predicted that when exposed to the oil, the coating partially passed through the zein layer but not the chitosan layer due to the rosemary oil. Zein is rich in nonpolar amino acids, which contributed to the water insolubility and improved the water vapour permeability of films and coatings [43]. The highest moisture content, absorbency and WVP were found for the uncoated sample. The neat chitosan paper coating had a WVP of about $510 \mathrm{~g} / \mathrm{m}^{2} \cdot 24 \mathrm{~h}$, but high WVP was observed in the 
chitosan film containing rosemary essential oil. Still, this enhancement in water passing through the film could be related to the cracked structure that was caused by the essential oil, as also proved by Abdollahi et al. [39]. Water vapour transfer could generally be affected by the hydrophilic part of the film and depends on the hydrophilic-hydrophobic ratio of the film components [51].

While the water barriers were higher on the chitosan and zein double coating due to the added zein, the WVP results showed low water vapour permeability in the coated samples, with the CZR sample being the lowest $\left(254 \mathrm{~g} / \mathrm{m}^{2} \cdot 24 \mathrm{~h}\right)$.

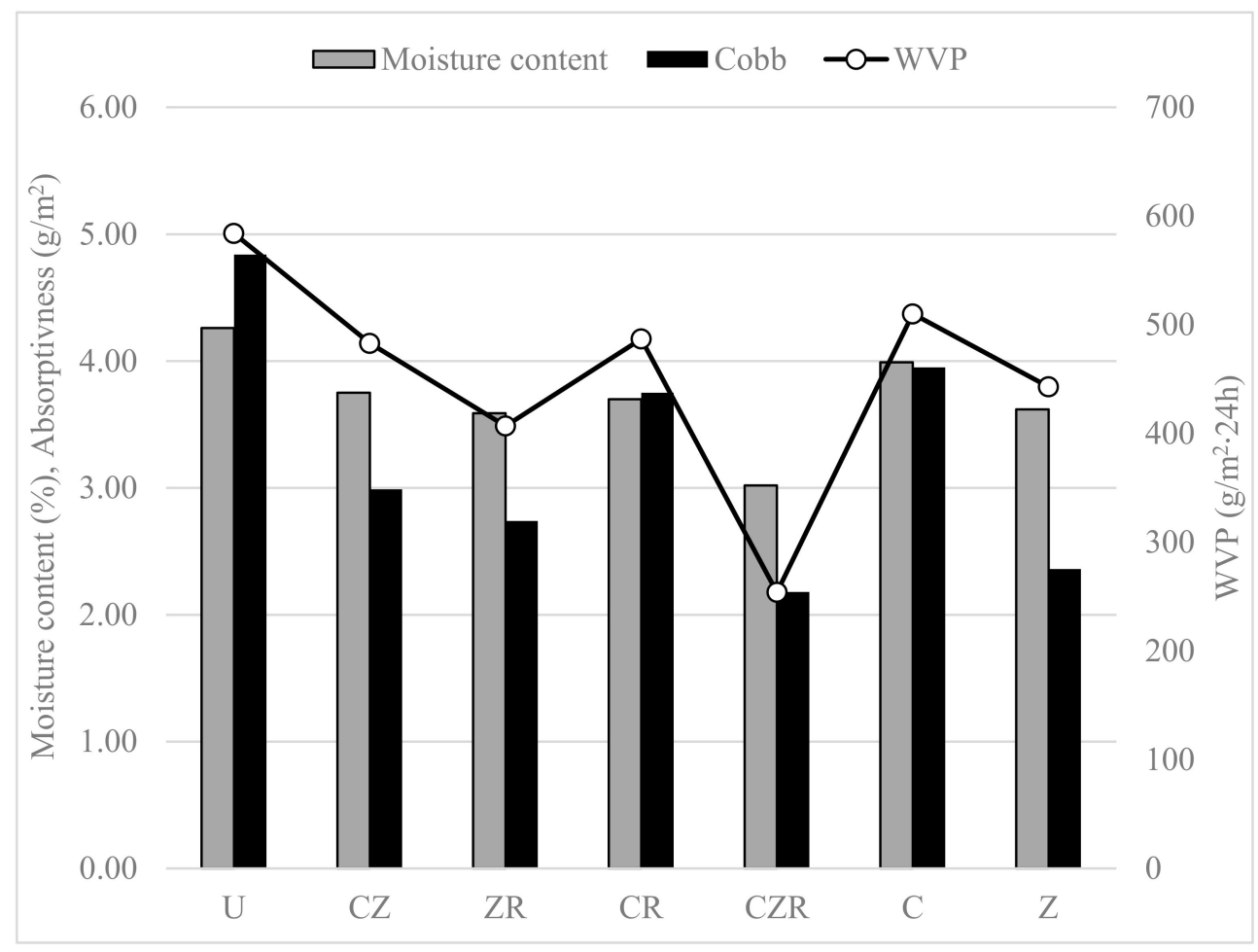

Figure 1. Moisture, absorptiveness, water vapour permeability (WVP) of the uncoated (U), chitosan and zein coated (CZ), blend zein and rosemary oil coated (ZR), blend chitosan and rosemary oil coated $(C R)$, chitosan and blend zein and rosemary oil coated (CZR), pure chitosan in one layer coated (C) and the pure zein in one layer coated $(Z)$ paper.

As shown in Figures 1 and 2, the CZR sample paper showed remarkable water and oil resistance. Zein-rosemary oil (ZR) coated paper had a poorer oil resistance compared to the chitosan-rosemary oil (CR) and the dual chitosan-zein (CZ) coated papers. Paper coated with only zein coating showed poorer oil resistance ( $46 \%$ area stained in $8 \mathrm{~h}$ ), which was the worst among the coated papers. These results proved the poor oil barrier properties of the zein coating. However, the papers coated with the addition of rosemary essential oil and chitosan showed better oil barrier properties.

As mentioned above, the CZR sample paper had a high oil resistance, which means that the oil partially passed through the zein layer, while the lower chitosan layer prevented the oil from passing through the paper substrate.

\subsection{Mechanical Properties}

Since paper is considered to be an anisotropic material because the fibres in the paper machine are aligned in the running direction (MD direction) and transverse to the fibre orientation, the so-called $\mathrm{CD}$ cross direction, tests were carried out in both directions. To guarantee a good runnability of paper web through the whole papermaking process, different strength properties were needed. Because base paper is wetted in the coating procedure, a good strength is required. The fibres and the fibre layers are connected by fibre bonds, which transmit shear forces and other network loads. The amount and size 
of the fibre bonds depends on the internal fibrillation, which also influences fibre swelling, elongation and flexibility [52]. The tensile-elongation behaviour depends on the moisture content of the paper. Namely, tensile strength increases, but the tear and elongation are reduced when the paper is dried.

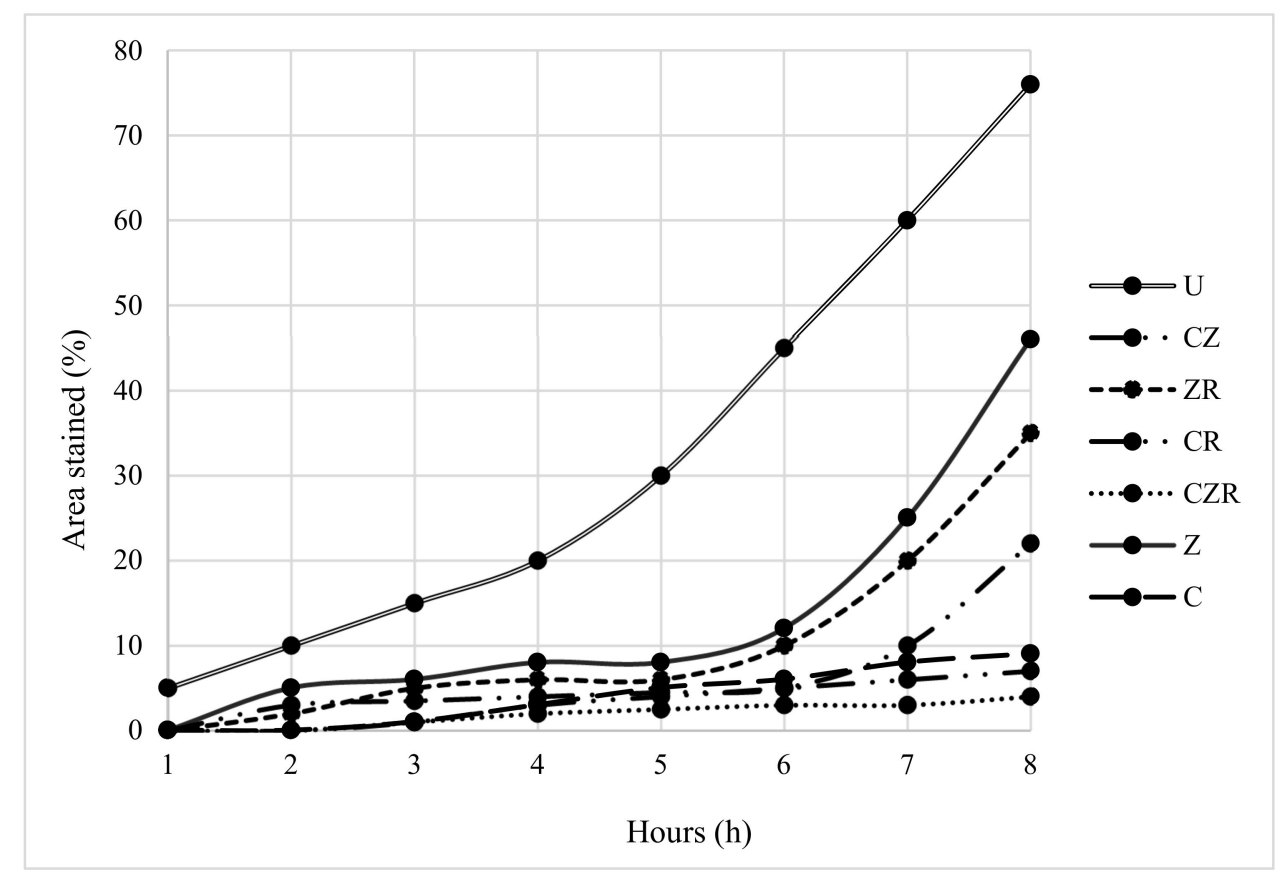

Figure 2. Grease resistance of the uncoated (U), chitosan and zein coated (CZ), blend zein and rosemary oil coated (ZR), blend chitosan and rosemary oil coated (CR), chitosan and blend zein and rosemary oil coated $(\mathrm{CZR})$, pure chitosan in one layer coated $(\mathrm{C})$ and the pure zein in one layer coated $(\mathrm{Z})$ paper.

Polysaccharides blend with other polymers, in varying proportions, and also improve the tensile properties. Tensile strength and elongation at break are very important in packaging materials due to the transport and handling of the products. The combination of chitosan, rosemary oil and zein had the highest value of TS and E compared to other coating combinations (Table 2). This indicated that the combination as a two-layer composition of the coating caused the structural change and the polymer matrix to become stiff and flexible, but not as predicted. Tensile strength and elongation increased slightly in all papers in both directions. This is also due to the interface of the coating materials with the molecular interactions between the fibres.

Bursting strength as well as bending and tear resistance were the highest for the dual layer of the CZR sample paper. The bursting strength was higher for $182 \mathrm{kPa}$, compared to the uncoated sample and $139 \mathrm{kPa}$ higher compared to the dual chitosan-zein coated paper. The sample CR had higher mechanical properties, indicating that chitosan with rosemary oil coating increased the stiffness of the paper. At only the pure chitosan and the pure zein coated samples were the improved tensile properties determined according to the uncoated sample. Compared to the other coated samples, the tensile properties of these two pure coatings were lower. In general, dual layer coating had an effect on the tensile strength of the paper, but it was equally drastic, compared to the other coated samples. The exception was the CZR dual coated paper which had the highest values.

The tensile and tear indices in the MD (Figure 3) and the CD (Figure 4) directions were determined for all samples. Due to the anisotropic properties of the paper, the tensile and tear indices for the samples were higher in the MD direction than in the CD direction. The CZR coated paper had the highest tensile and tear indices in both directions. As expected, the lowest indices were for the uncoated sample in both directions. Compared to other coated samples, pure chitosan and pure zein samples had the lowest indices. 
Table 2. Tensile strength (TS), elongation (E), bursting strength, bending and tear resistance in the cross direction (CD) and machine direction (MD) of the uncoated (U), chitosan and zein coated (CZ), blend zein and rosemary oil coated (ZR), blend chitosan and rosemary oil coated (CR), chitosan, blend zein and rosemary oil coated (CZR), pure chitosan in one layer coated $(C)$ and the pure zein in one layer coated (Z) paper.

\begin{tabular}{|c|c|c|c|c|c|c|c|c|c|}
\hline \multirow[t]{2}{*}{ Sample } & \multicolumn{2}{|c|}{ TS (MPa) } & \multicolumn{2}{|c|}{$E(\%)$} & \multicolumn{2}{|c|}{$\begin{array}{l}\text { Bending Resistance } \\
\text { (No. of Bendings) }\end{array}$} & \multicolumn{2}{|c|}{$\begin{array}{l}\text { Tear Resistance } \\
(\mathrm{mN})\end{array}$} & \multirow{2}{*}{$\begin{array}{c}\text { Bursting } \\
\text { Strength } \\
\text { (kPa) }\end{array}$} \\
\hline & MD & CD & MD & CD & MD & CD & MD & CD & \\
\hline $\mathrm{U}$ & $25 \pm 0.5$ & $58 \pm 0.7$ & $3.7 \pm 0.2$ & $2.0 \pm 0.7$ & $890 \pm 9$ & $1084 \pm 0.5$ & $315 \pm 1$ & $463 \pm 1$ & $307 \pm 1$ \\
\hline $\mathrm{CZ}$ & $34 \pm 1.1$ & $63 \pm 0.8$ & $5.0 \pm 0.3$ & $3.8 \pm 0.3$ & $2097 \pm 5$ & $4314 \pm 2$ & $382 \pm 2$ & $506 \pm 2$ & $350 \pm 1$ \\
\hline $\mathrm{ZR}$ & $33 \pm 0.9$ & $64 \pm 1.1$ & $5.2 \pm 0.5$ & $3.9 \pm 0.4$ & $2104 \pm 3$ & $5716 \pm 5$ & $389 \pm 2$ & $537 \pm 0.5$ & $353 \pm 2$ \\
\hline CR & $36 \pm 1.3$ & $69 \pm 0.6$ & $5.4 \pm 0.2$ & $4.1 \pm 0.6$ & $2125 \pm 7$ & $5759 \pm 8$ & $392 \pm 4$ & $544 \pm 6$ & $362 \pm 1$ \\
\hline CZR & $44 \pm 1.2$ & $75 \pm 0.7$ & $7.1 \pm 0.6$ & $6.0 \pm 0.1$ & $2517 \pm 8$ & $5843 \pm 9$ & $490 \pm 3$ & $637 \pm 4$ & $489 \pm 3$ \\
\hline C & $31 \pm 1.1$ & $63 \pm 0.5$ & $4.0 \pm 0.2$ & $2.4 \pm 0.3$ & $3108 \pm 8$ & $5239 \pm 7$ & $345 \pm 2$ & $533 \pm 4$ & $362 \pm 2$ \\
\hline Z & $30 \pm 1.0$ & $62 \pm 0.4$ & $3.9 \pm 0.3$ & $2.2 \pm 0.3$ & $2915 \pm 4$ & $4894 \pm 4$ & $331 \pm 2$ & $527 \pm 1$ & $358 \pm 2$ \\
\hline
\end{tabular}

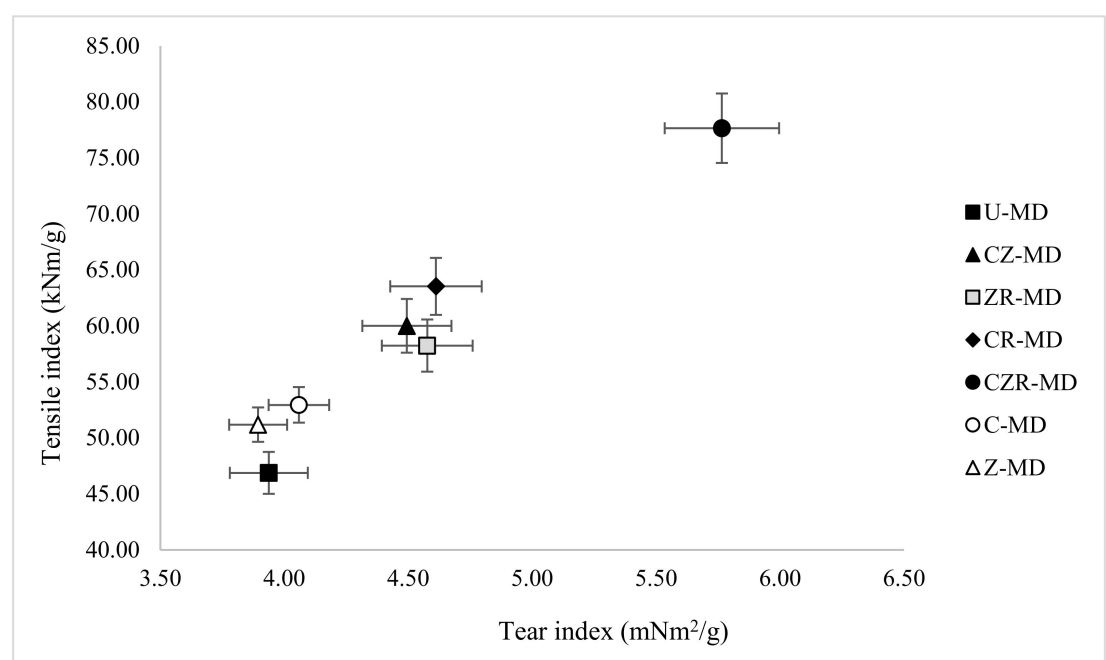

Figure 3. Tensile and tear indices for the uncoated (U), chitosan and zein coated (CZ), blend zein and rosemary oil coated (ZR), blend chitosan and rosemary oil coated (CR), chitosan and blend zein and rosemary oil coated (CZR) paper, pure chitosan in one layer coated $(C)$ and the pure zein in one layer coated (Z) paper in the MD direction.

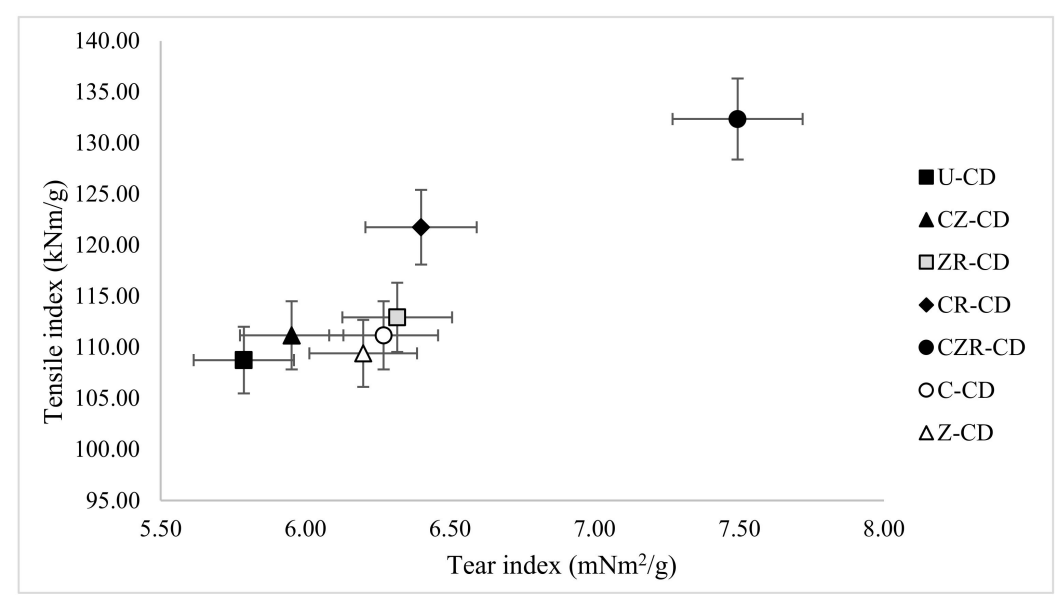

Figure 4. Tensile and tear indices for the uncoated (U), chitosan and zein coated (CZ), blend zein and rosemary oil coated (ZR), blend chitosan and rosemary oil coated (CR), chitosan, blend zein and rosemary oil coated (CZR) paper, pure chitosan in one layer coated $(C)$ and the pure zein in one layer coated $(Z)$ paper in the $C D$ direction. 
From this it can be concluded that the CZR sample is suitable as a packaging material as it can absorb the normal stresses that can occur during application, transport and use.

\subsection{Thermogravimetric Analysis (TGA)}

The thermogravimetric curves of uncoated and coated papers are presented in Figure 5. The initial weight loss for the uncoated paper was observed between 250 and $350{ }^{\circ} \mathrm{C}$. Thermal analysis showed an improvement in thermal stability for a dual layer of CZR paper coating, compared to the blended chitosan-rosemary and zein-rosemary coating. Moreover, the whole weight loss for the uncoated paper could be divided into three stages. In the first stage, in the range of $0-100{ }^{\circ} \mathrm{C}$, it could be attributed to the loss of water from the surface. The second weight loss was observed around $350{ }^{\circ} \mathrm{C}$. In the samples with rosemary oil (CR and ZR) the second stage was around $100-200{ }^{\circ} \mathrm{C}$ and showed less weight loss. Finally the coated samples showed the third weight loss in the range between 250 and $400{ }^{\circ} \mathrm{C}$. In samples with added chitosan (CZ, CR, C), this was due to the degradation of the chitosan polymer chain, which could be due to the removal of the acetic acid used in the chitosan solution [53].

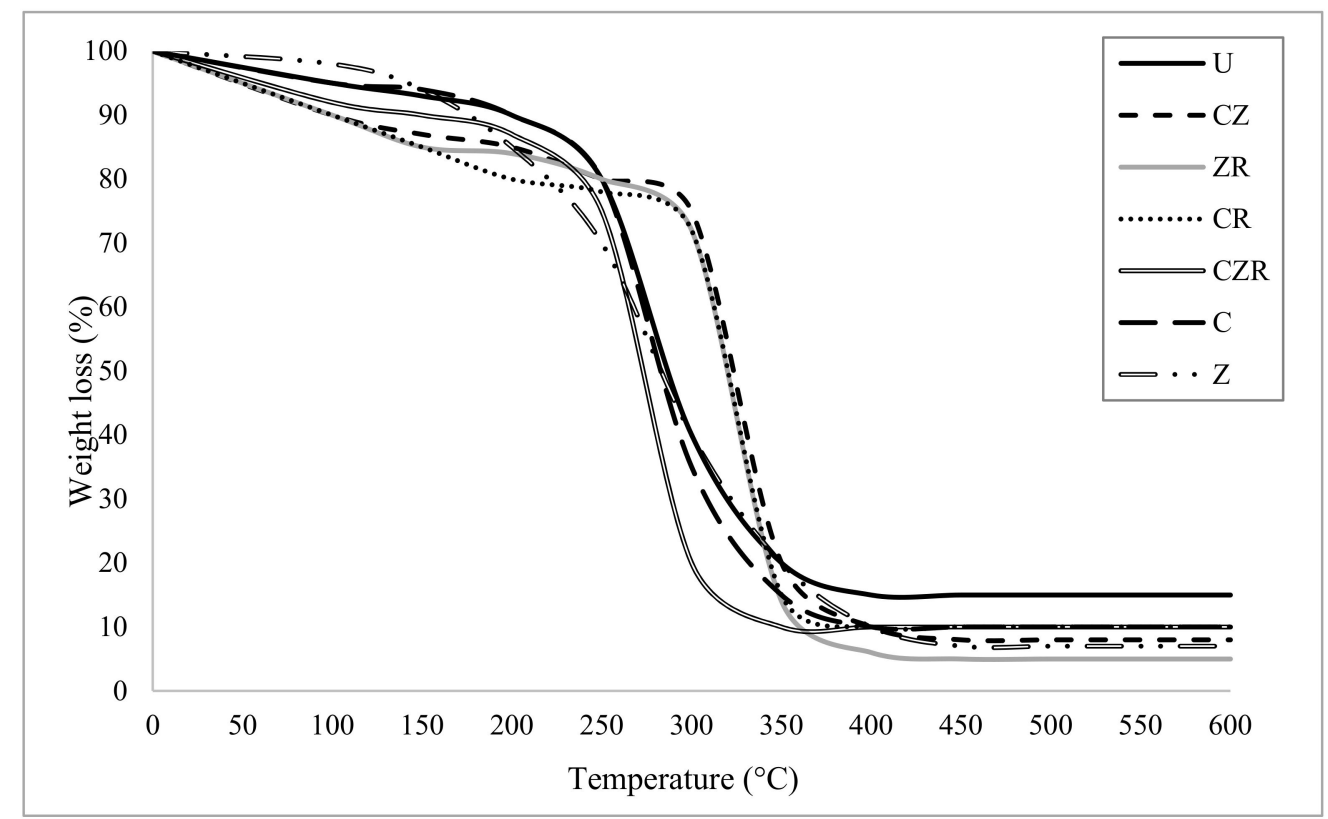

Figure 5. Thermogravimetric analysis (TGA) curves of the uncoated (U), chitosan and zein coated (CZ), blend zein and rosemary oil coated (ZR), blend chitosan and rosemary oil coated (CR), chitosan and blend zein, rosemary oil coated (CZR), pure chitosan in one layer coated (C) and the pure zein in one layer coated $(Z)$ paper.

At coatings with added zein, two weight loss regions occurred. The first one occurred in the range of $100-200{ }^{\circ} \mathrm{C}$ due to water loss and the second one occurred around $400{ }^{\circ} \mathrm{C}$. The incorporation of rosemary essential oil in the polymer matrix led to a two-step degradation process. The first degradation step was between 70 and $190^{\circ} \mathrm{C}$, corresponded to the degradation of rosemary oil [46]. The small weight loss during the first step $\left(10-20^{\circ} \mathrm{C}\right)$ might be due to the gradual evaporation of essential oil moisture [54].

At the dual layer sample (CZR), no weight loss was observed below $400{ }^{\circ} \mathrm{C}$, which indicates that the dual layer coated paper is thermally stable and could be used for further packaging application (for example oven).

\subsection{SEM}

To explore and understand the morphology and behaviour at the microscopic level, the samples were analysed by a scanning electron microscope. The micrographs of the uncoated and coated papers 
are presented in Figure 6. All the figures show the paper surface and coatings at $500 \times$ magnification and $10 \mathrm{kV}$ voltage. The images confirm the statements about the objectives of coating.

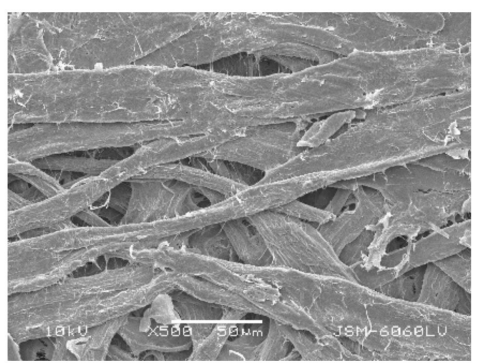

(a)

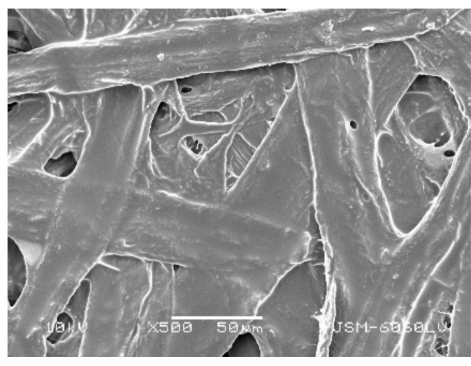

(d)

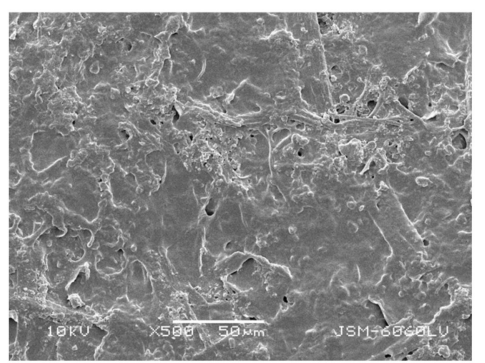

(b)

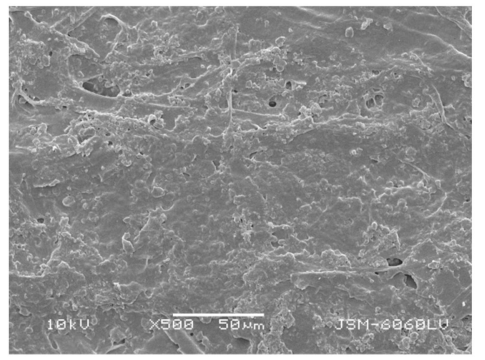

(e)

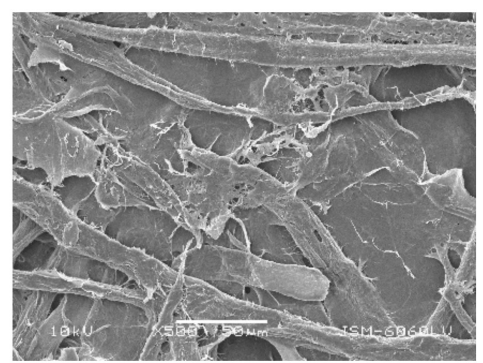

(c)

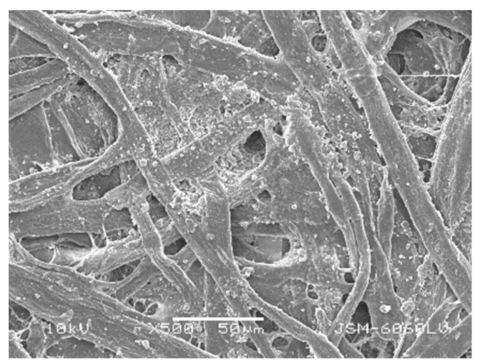

(f)

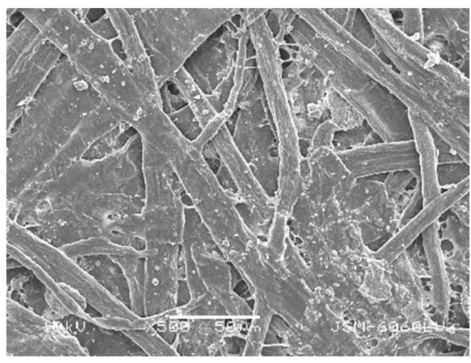

(g)

Figure 6. SEM micrographs of the uncoated (a), chitosan and zein coated (b), blend zein and rosemary oil coated (c), blend chitosan and rosemary oil coated (d), chitosan and blend zein and rosemary oil coated (e), pure chitosan in one layer coated (f) and the pure zein in one layer coated (g) paper, at magnification $500 \times$.

The surface properties of the coated papers correspond to the changes in mechanical, water and oil resistance. The absorption, thickness, moisture and roughness of uncoated paper have a great influence on the properties of the coatings. A good fibre coverage translates into the coated paper's smoothness. If the coating weight distribution is uneven, many properties can deteriorate after coating, which can affect the printing process (uneven print image and mottling).

From the micrographs, it is clear that the dual CRZ and CZ samples had a lower surface roughness, that they were smoother and no pores were observed. From the SEM micrographs it is clearly visible that the layered coating has a more uniform surface, which provides a lower moisture content and thus absorption capacity. It also has an influence on water vapour permeability and grease resistance. These results are consistent with the changes in the mechanical and water barrier properties of the coated samples. The figures also show that the chitosan content of the composite filled the surface and closed the pores compared to the other coated samples. As the number of layers increased, an increasingly continuous morphology and smooth surface coverage of the fibres was observed. 


\section{Conclusions}

A detailed characterisation of the different bio-based paper coatings was carried out. We successfully developed new mixtures of coatings with zein, chitosan and rosemary essential oil.

The data of the WVP showed that the addition of the rosemary oil to the coating solutions had a good effect on the water and the oil barrier properties. The results showed increased oil barrier properties in the papers coated with the zein-rosemary oil coating. Reduced water permeability in the papers coated with chitosan-rosemary oil coating solution was determined.

All the coated papers showed a high thermal stability, especially the papers coated layer-by-layer with chitosan, zein and rosemary oil solution. At the same time, the tensile properties increased, even more so with the two-layer coatings. The greatest structural change was induced by the composition of the two-layer coating in the CZR and CZ-coated papers, which promoted the closing of the structure and pore sizes.

The double coating with rosemary essential oil could also be a good example as a repellent active packaging material. Zein, however, is water-repellent but laces oil resistance and on the other hand there is chitosan with opposite properties.

With the addition of the essential oil, we assume that coated paper could be used as a natural repellent. In the future, the effect of the analysed dual coating against insect infestation will be analysed.

Author Contributions: Conceptualization, U.V.B.; formal analysis, U.V.B. and K.T.; investigation, U.V.B. and K.T.; supervision, U.V.B.; validation, U.V.B. and K.T.; writing-original draft preparation, U.V.B. and K.T.; writing-review and editing, U.V.B. All authors have read and agreed to the published version of the manuscript.

Funding: This research received no external funding.

Acknowledgments: The authors would like to thank Department of Textiles, Graphic Arts and Design, Faculty of Natural Sciences and Engineering, University of Ljubljana for the support.

Conflicts of Interest: The authors declare no conflict of interest.

\section{References}

1. Farhat, W.; Venditti, R.A.; Hubbe, M.; Taha, M.; Becquart, F.; Ayoub, A. A review of water-resistant hemicellulose-based materials: Processing and applications. ChemSusChem 2017, 10, 305-323. [CrossRef]

2. Shankar, S.; Rhim, J.W. Effects of poly (butylene adipate-co-terephthalate) coating on the water resistant, mechanical, and antibacterial properties of Kraft paper. Prog. Org. Coat. 2018, 123, 153-159. [CrossRef]

3. Gicquel, E.; Martin, C.; Yanez, J.G.; Bras, J. Cellulose nanocrystals as new bio-based coating layer for improving fiber-based mechanical and barrier properties. J. Mater. Sci. 2017, 52, 3048-3061. [CrossRef]

4. Ma, S.; Li, T.; Liu, X.; Zhu, J. Research progress on bio-based thermosetting resins. Polym. Internat. 2016, 65, 164-173. [CrossRef]

5. Helanto, K.E.; Matikainen, L.; Talja, R.; Rojas, O.J. Bio-based polymers for sustainable packaging and biobarriers: A critical review. BioResources 2019, 14, 4902-4951.

6. Koppolu, R.; Lahti, J.; Abitbol, T.; Swerin, A.; Kuusipalo, J.; Toivakka, M. Continuous processing of nanocellulose and polylactic acid into multilayer barrier coatings. ACS Appl. Mater. Inter. 2019, 11, 11920-11927. [CrossRef] [PubMed]

7. Vrabič Brodnjak, U. Influence of ultrasonic treatment on properties of bio-based coated paper. Prog. Org. Coat. 2017, 103, 93-100. [CrossRef]

8. Bordenave, N.; Grelier, S.; Coma, V. Hydrophobization and antimicrobial activity of chitosan and paper-based packaging material. Biomacromolecules 2010, 11, 88-96. [CrossRef]

9. Bordenave, N.; Grelier, S.; Pichavant, F.; Coma, V. Water and moisture susceptibility of chitosan and paper-based materials: Structure-property relationships. J. Agric. Food Chem. 2007, 55, 9479-9488. [CrossRef]

10. Xu, Y.X.; Kim, K.M.; Hanna, M.A.; Nag, D. Chitosan-starch composite film: Preparation and characterization. Ind. Crop. Prod. 2005, 21, 185-192. [CrossRef]

11. Wang, S.; Jing, Y. Effects of a chitosan coating layer on the surface properties and barrier properties of kraft paper. BioResources 2016, 11, 1868-1881. [CrossRef] 
12. Ham-Pichavant, F.; Sèbe, G.; Pardon, P.; Coma, V. Fat resistance properties of chitosan-based paper packaging for food applications. Carbohyd. Polym. 2005, 61, 259-265. [CrossRef]

13. Rastogi, V.K.; Samyn, P. Bio-based coatings for paper applications. Coatings 2015, 5, 887-930. [CrossRef]

14. Reis, A.B.; Yoshida, C.M.; Reis, A.P.C.; Franco, T.T. Application of chitosan emulsion as a coating on Kraft paper. Polym. Int. 2011, 60,963-969. [CrossRef]

15. Mujtaba, M.; Morsi, R.E.; Kerch, G.; Elsabee, M.Z.; Kaya, M.; Labidi, J.; Khawar, K.M. Current advancements in chitosan-based film production for food technology; A review. Int. J. Biol. Macromol. 2019, 121, 889-904. [CrossRef]

16. Cherpinski, A.; Torres-Giner, S.; Cabedo, L.; Méndez, J.A.; Lagaron, J.M. Multilayer structures based on annealed electrospun biopolymer coatings of interest in water and aroma barrier fiber-based food packaging applications. J. Appl. Polym. Sci. 2018, 135, 45501. [CrossRef]

17. Kopacic, S.; Walzl, A.; Zankel, A.; Leitner, E.; Bauer, W. Alginate and chitosan as a functional barrier for paper-based packaging materials. Coatings 2018, 8, 235. [CrossRef]

18. Hamdani, S.S.; Li, Z.; Rabnawaz, M.; Kamdem, D.P.; Khan, B.A. Chitosan-graft-polydimethylsiloxane/zein coatings for the fabrication of environmentally friendly oil-and water-resistant paper. ACS Sustain. Chem. Eng. 2020. [CrossRef]

19. Wang, Y.; Zhang, R.; Ahmed, S.; Qin, W.; Liu, Y. Preparation and characterization of corn starch bio-active edible packaging films based on zein incorporated with orange-peel oil. Antioxidants 2019, 8, 391. [CrossRef]

20. Kashiri, M.; Asadi, H.; Maghsoudlou, Y.; Mirzaei, H.; Alsoy Altinkaya, S. Characteristics of kraft papers coated with protein solutions containing tea extract powder with a layer-by-layer technique. Food Sci. Technol. 2019, 16, 85-197.

21. Kashiri, M.; Cerisuelo, J.P.; Domínguez, I.; López-Carballo, G.; Muriel-Gallet, V.; Gavara, R.; Hernández-Muñoz, P. Zein films and coatings as carriers and release systems of Zataria multiflora Boiss. essential oil for antimicrobial food packaging. Food Hydrocolloid. 2017, 70, 260-268. [CrossRef]

22. Li, Y.; Bai, Y.; Huang, J.; Yuan, C.; Ding, T.; Liu, D.; Hu, Y. Airglow discharge plasma treatment affects the surface structure and physical properties of zein films. J. Food Eng. 2020, 273, 109813. [CrossRef]

23. Gagon, A.T.; Britt, D.W.; Bastarrachea, L.J. Zein-modified antimicrobial polypropylene: Characterization and reusability upon UV-A light exposure. LWT 2020, 121, 108983. [CrossRef]

24. Zhang, L.; Liu, Z.; Wang, X.; Dong, S.; Sun, Y.; Zhao, Z. The properties of chitosan/zein blend film and effect of film on quality of mushroom (Agaricus bisporus). Postharvest Biol. Tec. 2019, 155, 47-56. [CrossRef]

25. Zhang, L.; Liu, Z.; Han, X.; Sun, Y.; Wang, X. Effect of ethanol content on rheology of film-forming solutions and properties of zein/chitosan film. Int. J. Biol. Macromol. 2019, 134, 807-814. [CrossRef] [PubMed]

26. Qu, L.; Chen, G.; Dong, S.; Huo, Y.; Yin, Z.; Li, S.; Chen, Y. Improved mechanical and antimicrobial properties of zein/chitosan films by adding highly dispersed nano-TiO 2 . Ind. Crops Prod. 2019, 130, 450-458. [CrossRef]

27. Ortiz, C.M.; Salgado, P.R.; Dufresne, A.; Mauri, A.N. Microfibrillated cellulose addition improved the physicochemical and bioactive properties of biodegradable films based on soy protein and clove essential oil. Food Hydrocolloid. 2018, 79, 416-427. [CrossRef]

28. Scartazzini, L.; Tosati, J.V.; Cortez, D.H.C.; Rossi, M.J.; Flôres, S.H.; Hubinger, M.D.; Monteiro, A.R. Gelatin edible coatings with mint essential oil (Mentha arvensis): Film characterization and antifungal properties. J. Food Sci. Technol. 2019, 56, 4045-4056. [CrossRef]

29. Atarés, L.; Chiralt, A. Essential oils as additives in biodegradable films and coatings for active food packaging. Trends Food Sci. Technol. 2016, 48, 51-62. [CrossRef]

30. Dashipour, A.; Razavilar, V.; Hosseini, H.; Shojaee-Aliabadi, S.; German, J.B.; Ghanati, K.; Khakpour, M.; Khaksar, R. Antioxidant and antimicrobial carboxymethyl cellulose films containing Zataria multiflora essential oil. Int. J. Biol. Macromol. 2015, 72, 606-613. [CrossRef]

31. Lee, M.H.; Kim, S.Y.; Park, H.J. Effect of halloysite nanoclay on the physical, mechanical, and antioxidant properties of chitosan films incorporated with clove essential oil. Food Hydrocolloid. 2018, 84, 58-67. [CrossRef]

32. Upadhyay, N.; Dwivedy, A.K.; Kumar, M.; Prakash, B.; Dubey, N.K. Essential oils as eco-friendly alternatives to synthetic pesticides for the control of Tribolium castaneum (Herbst) (Coleoptera: Tenebrionidae). J. Essent. Oil Bear. Plants 2018, 21, 282-297. [CrossRef]

33. Tavares, M.; da Silva, M.R.M.; de Siqueira, L.B.D.O.; Rodrigues, R.A.S.; Bodjolle-d'Almeida, L.; Dos Santos, E.P.; Ricci-Júnior, E. Trends in insect repellent formulations: A review. Int. J. Pharm. 2018, 539, 190-209. [CrossRef] [PubMed] 
34. Turasan, H.; Sahin, S.; Sumnu, G. Encapsulation of rosemary essential oil. LWT-Food Sci. Technol. 2015, 64, 112-119. [CrossRef]

35. Licciardello, F.; Muratore, G.; Suma, P.; Russo, A.; Nerín, C. Effectiveness of a novel insect-repellent food packaging incorporating essential oils against the red flour beetle (Tribolium castaneum). Innov. Food Sci. Emerg. 2013, 19, 173-180. [CrossRef]

36. Abdollahi, M.; Rezaei, M.; Farzi, G. A novel active bionanocomposite film incorporating rosemary essential oil and nanoclay into chitosan. J. Food Eng. 2012, 111, 343-350. [CrossRef]

37. Alizadeh-Sani, M.; Khezerlou, A.; Ehsani, A. Fabrication and characterization of the bionanocomposite film based on whey protein biopolymer loaded with $\mathrm{TiO}_{2}$ nanoparticles, cellulose nanofibers and rosemary essential oil. Ind. Crop Prod. 2018, 124, 300-315. [CrossRef]

38. Sanuja, S.; Agalya, A.; Umapathy, M.J. Synthesis and characterization of zinc oxide-neem oil-chitosan bionanocomposite for food packaging application. Int. J. Biol. Macromol. 2015, 74, 76-84. [CrossRef]

39. Abdollahi, M.; Rezaei, M.; Farzi, G. Improvement of active chitosan film properties with rosemary essential oil for food packaging. Int. J. Food Sci. Technol. 2012, 47, 847-853. [CrossRef]

40. Siripatrawan, U.; Harte, B.R. Physical properties and antioxidant activity of an active film from chitosan incorporated with green tea extract. Food Hydrocoll. 2010, 24, 770-775. [CrossRef]

41. Pires, J.R.A.; de Souza, V.G.L.; Fernando, A.L. Chitosan/montmorillonite bionanocomposites incorporated with rosemary and ginger essential oil as packaging for fresh poultry meat. Food Packag. Shelf Life. 2018, 17, 142-149. [CrossRef]

42. Lee, B.H.; Lee, S.E.; Annis, P.C.; Pratt, S.J.; Park, B.S.; Tumaalii, F. Fumigant toxicity of essential oils and monoterpenes against the red flour beetle, Tribolium castaneum Herbst. J. Asia Pac. Entomol. 2002, 5, 237-240. [CrossRef]

43. ISO 536-Paper and Board-Determination of Grammage; International Organization for Standardization: Geneva, Switzerland, 2012.

44. ISO 534-Paper and Board-Determination of Thickness, Density and Specific Volume; International Organization for Standardization: Geneva, Switzerland, 2017.

45. ISO 287-Paper and Board-Determination of Moisture Content of a Lot-Oven-Drying Method; International Organization for Standardization: Geneva, Switzerland, 2017.

46. ISO 535-Paper and Board—Determination of Water Absorptiveness—Cobb Method; International Organization for Standardization: Geneva, Switzerland, 2014.

47. ISO 2528-Sheet Materials_Determination of Water Vapour Transmission Rate (WVTR)—Gravimetric (Dish) Method; International Organization for Standardization: Geneva, Switzerland, 2017.

48. TAPPI T511-Folding Endurance of Paper (MIT Tester); TAPPI organization: Peachtree Corners, GA, USA, 2006.

49. EN ISO 13938/2:2019-Bursting Properties of Fabrics_Part 2: Pneumatic Method for Determination of Bursting Strength and Bursting Distension; International Organization for Standardization: Geneva, Switzerland, 2019.

50. ISO 1974:2012 Paper-Determination of Tearing Resistance_Elmendorf Method; International Organization for Standardization: Geneva, Switzerland, 2019.

51. Norajit, K.; Kim, K.M.; Ryu, G.H. Comparative studies on the characterization and antioxidant properties of biodegradable alginate films containing ginseng extract. J. Food Eng. 2010, 98, 377-384. [CrossRef]

52. Gullichsen, J.; Paulapuro, H.; Lehtinen, E. Pigment coating and surface sizing of paper. Book 2000, 11, 2-61.

53. Hong, P.Z.; Li, S.D.; Ou, C.Y.; Li, C.P.; Yang, L.; Zhang, C.H. Thermogravimetric analysis of chitosan. J. Appl. Polym. Sci. 2007, 105, 547-551. [CrossRef]

54. Qin, Y.; Li, W.; Liu, D.; Yuan, M.; Li, L. Development of active packaging film made from poly (lactic acid) incorporated essential oil. Prog. Org. Coat. 2017, 103, 76-82. [CrossRef]

(C) 2020 by the authors. Licensee MDPI, Basel, Switzerland. This article is an open access article distributed under the terms and conditions of the Creative Commons Attribution (CC BY) license (http://creativecommons.org/licenses/by/4.0/). 